\title{
Effects of Communication Impairments on Knowledge Acquisition
}

\author{
Emily Ayieta Ondondo \\ Jaramogi Oginga Odinga University of Science and Technology, Bondo, Kenya
}

\begin{abstract}
Knowledge acquisition is facilitated through communication and communication occurs through language. However, in individuals with communication impairments, effective communication is adversely tempered with. This implies that communication impairments would affect knowledge acquisition. The question, however, is how this happens? Little effort has been made to answer this question, as revealed by the literature. In the quest to establish the effects of communication impairments on knowledge acquisition, this paper adopts a descriptive design and critically analyzes how communication disorders affect knowledge acquisition. It does this by examining how different communication impairments interact with different strategies proposed for knowledge acquisition and the resultant outcome. The results show that communication impairments hinder knowledge acquisition. They create barriers that prevent efficient execution of the various strategies involved in acquiring knowledge. The paper then provides some practical suggestions on how to deal with the ensuing problem with the aim of promoting knowledge acquisition.
\end{abstract}

Keywords: knowledge, acquisition, communication, impairment, language, aphasia

\section{Introduction}

It is alleged that human beings enter into the world with a blank mind (Akmajian, Demers, Farmer, \& Harnish, 2010; Anderson, 1993). Through knowledge acquisition they build up and understand information about the world they live in. Knowledge acquisition proceeds in stages, is incremental in nature and involves the formulation of information theories about the world and revision of already formulated theories to incorporate new information (Kuhn, Garcia-Mila, Zohar, \& Andersen, 1995). Knowledge acquisition is, therefore, a process of hypothesis formulation and testing.

Knowledge acquisition occurs when the individual interacts with the world, both physical and social. However, how the individual performs in this interaction determines how s/he succeeds in acquiring knowledge about that world. The most crucial factor that determines interaction performance is communication (Brewer \& Samarapungavan, 1991; Carey, 1985, 1986; Wellman \& Gelman, 1992)

Communication entails the passing of information to and from the world and the individual. It is a complex process that involves speaking, hearing, listening, understanding, social skills, reading, and writing. Effective

Emily Ayieta Ondondo, lecturer, Ph.D., Department of Linguistics, Languages and Literature, Jaramogi Oginga Odinga University of Science and Technology. 
communication seeks for the message to be received (heard or read), understood, accepted, and acted upon. Failure to achieve this leads to frustrations (Stanton, 2009).

The message we want to pass across is a thought in our head/mind (acquired knowledge). We use words to express this message and words constitute language. Language, therefore, is central and vital to communication and knowledge acquisition.

Language is developed or acquired by human beings naturally and is located in the brain (Chomsky, 1986). The process of using and understanding language is a complex and cognitive one. Problems in this process adversely affect communication and knowledge acquisition. Many of these problems result from language and speech disorders.

Interests in the study of language and speech disorders differ according to the objective in question. The speech pathologist, for instance, is concerned with diagnosis and management of the disorder. The linguist, on the other hand, is interested in finding out the extent to which the disorder determines the location of language in the brain. Little interest, however, has been paid on how the disorder affects communication and knowledge acquisition.

This paper describes some of the main communication impairments resulting from language and speech disorders, with the major objective of determining their effects on knowledge acquisition. The paper is organized as follows. Section 2 briefly describes the process of knowledge acquisition, highlighting the strategies used in acquiring knowledge. Section 3 discusses some of the main and common language and speech disorders. Section 4 embarks on showing how language and speech disorders affect knowledge acquisition. Suggestions on how to help achieve knowledge acquisition in individuals with communication impairments is provided in section 5 . Finally, section 6 is a conclusion to the paper.

\section{The Process of Knowledge Acquisition}

Knowledge acquisition is a process in which knowledge is organized, from an early age, into theories that are elaborated and revised over time and that serve as vehicles for understanding the world. What individuals already know and how that knowledge is organized constrains what and how new knowledge will be acquired (Cheng \& Nisbett, 1993; Kuhn et al., 1995; Medin, 1989; Wisniewski \& Medin, 1994). Knowledge acquisition, therefore, occurs through a process of theory formation and revision.

The question, however, is when and how does new evidence lead to modification of existing theories? There are mechanisms by means of which knowledge is acquired. Keil $(1988,1989,1991)$ argues that knowledge acquisition occurs through theory guided networks of associations observed in the environment that are overlaid with causal beliefs. Following Keil, Kuhn et al. (1995) assert that the mechanisms of knowledge acquisition entail the coordination of new evidence with an existing network of theories. They argue that to achieve this coordination an individual uses the strategies of inductive causal inference and scientific reasoning. These strategies encompass three competences: strategic competence, metastrategic competence, and metacognitive competence.

Strategic competence is the competence that executes investigative and inference strategies that yield valid conclusions. This competence involves the basic strategies of valid intent, coordination of inference and intent, evidence-based inference, use of comparative evidence, controlled comparison and valid inclusion and exclusion 
inference. What is important here is the ratio of usage of valid and invalid strategies, and not the ability to execute correct strategies. This is because even when strategic competence is well in place, strategies are not consistently applied. This shows that more is involved in competent performance than just the ability to execute correct strategies. However, the more valid strategies are used as opposed to invalid strategies, the higher the rate at which knowledge is acquired (Barrett, Abdi, Murphy, \& Gallagher, 1993; Kuhn et al., 1995).

Metastrategic competence has to do with the ability of an individual to select the strategies to apply. It has three aspects.

First, metastrategic competence dictates the strategies that are used, and involves understanding the significance of a strategy (Kuhn, 1983; Moshman, 1990) rather than knowing how to execute a strategy. Metastrategic competence, therefore, includes understanding of the value, necessity, and limitations of a strategy. That is, knowing how, when, and why the strategy should be used.

Second, metastrategic competence applies to invalid strategies as well as valid ones. An individual needs to recognize why invalid strategies do not work or why they work inefficiently in order to avoid using them. Similarly, an individual should understand the need to use valid strategies and the pitfalls of resorting to the less adequate ones (Kuhn et al., 1995).

Third, metastrategic competence has to do with understanding the task. Given that strategies are applied in the service of the goals and purposes of particular tasks, features of potential strategies must be coordinated with features of the task to yield skilled performance. If this understanding is weak or absent, performance is bound to suffer (Kuhn et al., 1995).

Metacognitive competence contrasts with metastrategic competence in that it involves reflection on the content of one's knowledge rather than its form. Metacognitive competence focuses on justifying assertions by identifying and retaining knowledge of their sources, that is, the bases for claiming them to be true. This accomplishment involves differentiating theory and evidence at a metacognitive level. Of critical importance is that the individual processes and represents the implications of new evidence as an entity, independent of belief, which also must be represented as a distinct entity and compared to the representation of evidence (Kuhn et al., 1995; Mahoney, 1976; Nissani \& Hoefler-Nissani, 1992).

As the preceding discussion shows, the process of knowledge acquisition is a complex and hard one. If it cannot be achieved easily in individuals with no communication impairments, then it must be harder to achieve in subjects with communication impairments.

\section{Language, Speech, and Hearing Disorders}

Different communication disorders lead to communication difficulties in various aspects of communication such as speech, language, literacy, social communication, fluency, and hearing (Bloom, 1988; Lahey, 1988). This section describes some of the disorders that lead to communication impairments. It begins by discussing the relationship between language, speech, and the brain.

\section{Language, Speech, and the Brain}

Language is located in the brain. The brain consists of two hemispheres (right and left) joined by the corpus callosum. Language processing and generation is in the left hemisphere. Specific areas of the brain are used for carrying out specific functions. The two most important areas of the brain for language are Broca's area and 
Wernicke's area. Broca's area is the location of grammar, particularly syntax, while Wernicke's area is the area where meaning is constructed (Akmajian et al., 2010; O’Grady, Archibald, Aronoff, \& Rees-Miller, 2001; Fromkin, Rodman, \& Hyams, 2013).

Speech comprehension and language production are neurolinguistic processes, given that language is located in the brain. In the former process, auditory input is received by ears and sent to the auditory cortex where it is processed. After processing, the signal is passed on to Wernicke's area, where the basic semantic structure of the utterance is constructed for interpretation of meaning. To execute language production the signal is then sent to Broca's area to be turned into language. From there it is sent to the motor cortex where the appropriate muscles and body parts are stimulated to produce language (O’Grady et al., 2001).

\section{Language Disorders}

Language disorders are divided into two groups, acquired and developmental language disorders.

Acquired language disorders. Acquired language disorders arise when something goes wrong with the brain, resulting in language problems. They are of different types, as the following discussion shows.

Aphasia. One of the most common acquired language disorders is aphasia. This is language problems caused by damage to the brain, usually through injury or a stroke. Specific language problems result depending on the area of the brain that is damaged.

Broca's aphasia. Damage to Broca's area causes Broca's aphasia, also known as "non-fluent” aphasia. Broca's area controls grammar-syntax, as mentioned in the preceding section. As a result, patients with Broca's aphasia speak haltingly and their speech is slow and labored. They have trouble getting words out and trouble constructing grammatical utterances. They are aware of the disorder and are very frustrated when trying to speak because they know what they are trying to say but cannot get it out. The most severe form is global aphasia where the subject is completely unable to speak (Akmajian et al., 2010; O’Grady et al., 2001).

Wernicke's aphasia. Wernicke's aphasia (also known as “fluent” aphasia) is impairment to Wernicke’s area. Wernicke's area controls meaning and is the location of word meaning. Wernicke's aphasics have major difficulties constructing meaningful utterances. Their speech is grammatical, rapid, and fluent, with normal intonation. But it is meaningless. It has little or no semantic content or cohesion. Wernicke's aphasics have difficulty understanding what is said to them. They often cannot follow simple instructions like "stand up and turn to your left”. Unlike Broca’s, Wernicke’s aphasics usually seem to be unaware of their problem (O’Grady et al., 2001).

Conduct aphasia. Conduct aphasia results from damage to the arcuate fasciculus, the fibres that link Wernicke's and Broca's areas. Conduct aphasics can construct meaning but they cannot communicate that properly to the part of the brain that turns the meaning into language. Conduct aphasics sound like Wernicke's aphasics. But unlike them they can understand perfectly well (O’Grady et al., 2001).

Acquired alexia and agraphia. Another type of acquired language disorders is acquired alexia and agraphia. These are impairments caused by brain damage. Alexia is an impairment of reading ability, while agraphia is an impairment of writing ability. These impairments are related to aphasia. Most Broca's aphasics show writing disturbances that are compared to their speaking deficits seen in spelling which corresponds to the pronunciation. Their spontaneous writing also tends to be ungrammatical. Their silent reading is very good but their loud reading 
shows the same telegraphic style as their spontaneous speech (Kahmi \& Catts, 1989; O’Grady et al., 2001).

Wernicke's aphasics also show reading and writing deficits that match their deficits in speaking and listening. Their writing is very good. Their written production, however, like their speaking makes little sense. Reading comprehension is severely impaired. They can see the letters and words but cannot make any sense of them (Akmajian et al., 2010; O’Grady et al., 2001).

Dyslexia. The third type of acquired language disorders that we discuss here is dyslexia. Acquired dyslexia follows from damage in and around the angular gyrus of the parietal lobe and does not relate to aphasia. This is the part of the brain that controls the ability of readers to maintain a set of spelling to sound rules that enables them to read new words aloud. These rules are important in the development of reading ability and in the addition of new words to our reading vocabulary (Akmajian et al., 2010; O’Grady et al., 2001).

Dyslexia occurs in two forms: phonological and surface dyslexia. Subjects with phonological dyslexia lose the ability to use spelling to sound rules. They can only read words that they have seen before. When they encounter new words they either do not read them or they produce a known word that is visually similar to the target. Surface dyslexia, on the other hand, is the opposite of phonological dyslexia. Subjects with this disorder are unable to recognize words as wholes. They process all words through a set of spelling to sound rules. They can easily read regularly spelled words but apply regular rules to irregularly spelled words and thus produce incorrect forms. They understand what they produce not what they see. If they read a word incorrectly they assign it a meaning that is appropriate to their incorrect pronunciation (Akmajian et al., 2010; O’Grady et al., 2001).

Developmental language disorders. These are language disorders that emerge in young children. They are of different types, as we show below.

Grammatical Specific Language Impairment (SLI). This involves impairment to grammatical aspects of language. It causes problems both in the production and judgement of the grammaticality of utterances (Akmajian et al., 2010; O’Grady et al., 2001; Fromkin et al., 2013).

William's syndrome. This is a rare genetic condition that is associated with mental retardation and an unusual facial appearance. Though language is largely unaffected in subjects with this condition, cognitive functioning is very poor (Akmajian et al., 2010; O’Grady et al., 2001; Fromkin et al., 2013).

Down's syndrome. This disorder reflects a general cognitive deficit resulting from general processing limitations and working memory deficit. In subjects with this condition language acquisition is delayed and appears to reach a ceiling, along with other cognitive abilities (Akmajian et al., 2010; O’Grady et al., 2001; Fromkin et al., 2013).

Autism. Autistic spectrum disorders are associated with pragmatic problems ranging from mild to severe. These disorders are linked with the theory of mind which has to do with the ability to expect/guess the thoughts of another person, or impart belief. Subjects with autism perform poorly on this aspect.

There are different manifestations of autism. Low-functioning autists may be nonverbal or monosyllabic. They may behave in an extremely antisocial manner from an early age. They lack the most basic social skills and cannot read. High-functioning autists may have near-normal linguistic ability, characterised by more subtle problems with pragmatics and intonation. They still tend to have social and conversational problems. Aspergers, on the other hand, have social problems, little interest in people or emotions, obsessions with mechanical objects, difficulty in sympathising/empathising with others and forming relationships, tendency to interpret everything literally, and 
problems with jokes and metaphor (Akmajian et al., 2010; O’Grady et al., 2001; Fromkin et al., 2013).

Pragmatic Language Impairment (PLI). Individuals with this disorder have very fluent expressive language. Their utterances are syntactically well-formed and phonologically intact. But they have impairment in the ability to express meaning relevant to the conversational situation and a striking inability to engage in communicative discourse. They understand short phrases and individual words, but their ability to understand connected discourse is impaired. They answer questions with irrelevant responses and have problems with humour and metaphor (Harris, 1994; O’Grady et al., 2001).

\section{Speech Disorders}

Many diverse structures and systems combine together to produce speech. They are all regulated by the nervous system. Therefore, any damage or disease that affects this system will disrupt the ability to produce speech, resulting in motor speech impairments. Children with these impairments are usually very difficult to understand and have many articulation errors. They have poor control of the muscles in the face and mouth which creates problems in articulating and combining sounds in the rapid way necessary for speech. Verbal apraxia and dysarthria are types of motor speech impairments. Verbal apraxia is the inability to perform coordinated movements with the tongue, lips, and jaw. Dysarthria results from impaired motor control of the throat, tongue, or lips (Alberta Health, 1993; Boberg \& Kully, 1985).

Another well known speech disorder is stuttering. This is a fluency impairment that results in the disruption of the flow and rhythm of speech. These disruptions may be repetitions of words or parts of words, prolongation of a sound, or unusually long hesitations between words. A person who stutters may also exhibit behaviors such as facial grimaces or unusual body movements (Alberta Health, 1993; Boberg \& Kully, 1985).

\section{Hearing Impairments}

Hearing impairments can be in the form of mild, moderate, severe, profound, or total hearing loss. The loss may be congenital or acquired during or after language acquisition, and may be fluctuating or progressive. Any degree or type of hearing reduces exposure to spoken language. This may delay the development of speech and language skills in children. This has academic implications for development of listening, speaking, reading, writing, and social skills (Davis \& Silverman, 1978).

\section{How Language and Speech Disorders Affect Knowledge Acquisition}

Communication skills are of vital importance in the society. Anything that interferes with communication creates serious problems for people including children (Day, 1985). Speech and language development are the primary elements of communication. Therefore, people need good speech and language skills to succeed in school and in life in general.

The discussion in the preceding sections shows that language is a cognitive module, just like knowledge acquisition. As a result, the communication impairments, resulting from language and speech disorders, discussed in section 3 have adverse consequences for knowledge acquisition.

All the disorders discussed in the preceding section directly affect the three competencies (strategic, metastrategic, and metacognitive) necessary for knowledge acquisition, as discussed in section 2 . They also have serious impacts on how persons with them function in their daily life including learning at school and interacting 
socially with others. All these have long term implications such as poor academic achievement, risk to mental health, reduced employment options and social isolation. People with communication impairment suffer frustration, anger, grief, embarrassment, low self-esteem, and less social success as they try to communicate their needs, ideas, and opinions.

\section{Achieving Knowledge Acquisition in Individuals With Communication Impairments}

There are three important interventions that can be put in place in order to help people with communication impairments achieve knowledge acquisition. The first and most important intervention is early and correct identification and handling of the impairment. To achieve this, there is need to seek the help of speech pathologists. These are specialists trained to assess, advise, treat, and advocate for people with communication impairment and their families. Early intervention, therefore, is the key to preventing or reducing the lifelong implications of communication impairments (Students Support Services, 2000).

The second intervention has to do with the use of appropriate individual strategies or measures when handling, dealing, and interacting with people with communication impairments. As an individual (teacher, parent, guardian, friend, etc.) there is need to be sensitive to the disorder that the subject has and learn to adopt and use approaches that help the subject be at ease with the disorder. For instance, one need not point out communication disorders to others but to show understanding, patience, and acceptance, as well as getting down to the physical level of the person as per their disorders (Students Support Services, 2000).

The use of communication techniques that help the subjects overcome their communication problems is important and helpful. A technique like questioning helps elicit a response from the subject and maintain the conversation. Modelling, in which the individual uses appropriate language during the conversation, provides opportunities for the subject to hear appropriate language. On the other hand, language expansion, which entails taking what the subject has said and expanding it to include more words, assists in increasing the repertoire of words the subject uses. This reinforces the subject's attempt to communicate and gives additional information on the topic to the subject (Students Support Services, 2000).

The third intervention advocates for the use of recommended strategies, specific to all communication impairments, to assist the subject handle the problem. There are manuals with well documented strategies relevant to how to deal with all communication impairments. They show strategies on how to help and support people with specific impairments. There are also specific strategies recommended for each communicative environment: school, home, or community. That is specific recommendations for speech pathologists, teachers, family member as well as other community members (Catts, 1991; Health and Welfare Canada, 1982; McCarney, Wunderlich, \& Bauer, 1993; Rosner, 1993; Students Support Services, 2000; Travis, 1971).

\section{Conclusion}

Communication impairments are more common than is thought. In most cases they are misunderstood and/or misdiagnosed. Without intervention communication impairments affect speech, language, literacy, and social communication. Speech involves saying the sounds in words and speaking fluently so that people can understand what is being said. Language entails the exchange of ideas using words, usually in spoken or written form. Literacy, on the other hand, concerns reading, understanding what is read and communicating in written 
form, while social communication has to do with how we communicate and involves interpreting the context of a conversation, understanding non-verbal information and the social rules of communication that are needed to develop a relationship with another person. All these aspects are important and relevant for knowledge acquisition. Any problems with them hinder knowledge acquisition as this endangers the different strategies of knowledge acquisition. There is, therefore, urgent need for the understanding, correct diagnosis, and therapeutic treatment of communication impairments. There is also need for urgent and timely help and support for individuals with communication impairments in order to help alleviate the long term effects of communication impairments on knowledge acquisition.

\section{References}

Akmajian, A., Demers, R., Farmer, A., \& Harnish, R. (2010). Linguistics: An introduction to language and communication (6th ed.). Cambridge: MIT Press.

Alberta Health. (1993). Speech language pathology information for teachers. Calgary, AB: Author.

Anderson, J. R. (1993). Rules of the mind. Hillsdale, NJ: Erlbaum.

Barrett, S., Abdi, H., Murphy, G., \& Gallagher, J. (1993). Theory-based correlations and their role in children's concepts. Child Development, 64, 1595-1616.

Bloom, L. (1988). What is language?. In M. Lahey (Ed.), Language disorders and language development (pp. 1-19). New York: Macmillan Publishing Company.

Boberg, E., \& Kully, D. (1985). Comprehensive stuttering program. San Diego, CA: College-Hill.

Brewer, W., \& Samarapungavan, A. (1991). Children’s theories vs. scientific theories: Differences in reasoning or differences in knowledge?. In R. Hoffman \& D. Palermo (Eds.), Cognition and the symbolic processes. Hillsdale, NJ: Erlbaum.

Carey, S. (1985). Are children fundamentally different kinds of thinkers and learners than adults?. In S. Chipman, J. Segal, \& R. Glaser (Eds.), Thinking and learning skills (Vol. 2). Hillsdale, NJ: Erlbaum.

Carey, S. (1986). Cognitive science and science education. American Psychologist, 41, 1123-1130.

Catts, H. W. (1991). Facilitating phonological awareness: Role of speech-language pathologists. Language, Speech, and Hearing Services in Schools, 22, 196-203.

Cheng, P., \& Nisbett, R. (1993). Pragmatic constraints on causal deduction. In R. Nisbett (Ed.), Rules for reasoning. Hillsdale, NJ: Erlbaum.

Chomsky, N. (1986). Knowledge of language. Cambridge: MIT Press.

Davis, H., \& Silverman, S. R. (1978). Hearing and deafness. New York: Holt, Rinehart and Winston.

Day, C. (1985). Educating exceptional children (4th ed.). Scarborough, ON: NelsonCanada.

Fromkin, V., Rodman, R., \& Hyams, N. (2013). An introduction to language (10th ed.). Boston, USA: Wadsworth Cengage Learning.

Harris, K. N. (1994). What is a speech-language pathologist?. Paper presented at an In service for Instructional Resource Teachers, Spaniards Bay, NF, Avalon North School District.

Health and Welfare Canada. (1982). Guidelines for the practice of language-speech pathology and audiology. Ottawa, ON: Author.

Kahmi, A., \& Catts, H. (1989). Reading disabilities: A developmental language perspective. Austin, TX: Pro-Ed.

Keil, F. (1988). Commentary. Human Development, 31, 35-43.

Keil, F. (1989). Concepts, kinds, and cognitive development. Cambridge, MA: Bradford.

Keil, F. (1991). The emergence of theoretical beliefs as constraints on concepts. In S. Carey \& R. Gelman (Eds.), The epigenesis of mind: Essays on biology and cognition. Hillsdale, NJ: Erlbaum.

Kuhn, D. (1983). On the dual executive and its significance in the development of developmental psychology. In D. Kuhn \& J. Meacham (Eds.), On the development of developmental psychology (contributions to human development) (Vol. 8). Basel: Karger.

Kuhn, D., Garcia-Mila, M., Zohar, A., \& Andersen, C. (1995). Strategies of knowledge acquisition. Society for Research in Child Development Monographs, 60(4), 1-157.

Lahey, M. (1988). Language disorders and language development. New York: Macmillan Publishing Company.

Mahoney, M. (Ed.). (1976). Scientist as subject: The psychological imperative. Cambridge, MA: Ballinger. 
McCarney, S. B., Wunderlich, K. C., \& Bauer, A. M. (1993). The pre-referral intervention manual (2nd ed.). Columbia, MO: Hawthorne Educational Services Inc..

Medin, D. (1989). Concepts and conceptual structure. American Psychologist, 44, 1469-1481.

Moshman, D. (1990). The development of metalogical understanding. In W. Overton (Ed.), Reasoning, necessity, and logic: Developmental perspectives. Hillsdale, NJ: Erlbaum.

Nissani, M., \& Hoefler-Nissani, D. (1992). Experimental studies of belief dependence of observations and of resistance to conceptual change. Cognition and Instruction, 9(2), 97-111.

O’Grady, W., Archibald, J., Aronoff, M., \& Rees-Miller, J. (2001). Contemporary linguistics: An introduction (4th ed.). Bedford: Martin's Press.

Rosner, J. (1993). Helping children overcome learning difficulties. New York: Walter \& Company.

Stanton, N. (2009). Mastering communication. New York: Palgrave Macmillan.

Students Support Services. (2000). Communication disorders handbook. Canada: Author.

Travis, L. E. (1971). Handbook of speech pathology and audiology. New York: Meredith Corporation.

Wellman, H., \& Gelman, S. (1992). Cognitive development: Foundational theories of core domains. Annual Review of Psychology, 43, 337-375.

Wisniewski, E., \& Medin, D. (1994). On the interaction of theory and data in concept learning. Cognitive Science, 18, $221-281$. 